\title{
1 The acute lag effects of elevated ambient air pollution on stillbirth 2 risk in Ulaanbaatar, Mongolia
}

3 Temuulen Enebish ${ }^{1}$, David Warburton ${ }^{2,3}$, Rima Habre ${ }^{4}$, Carrie Breton ${ }^{4}$, Nomindelger Tuvshindorj ${ }^{5}$,

4 Gantuya Tumur 5 , Bayalag Munkhuu ${ }^{5}$, Meredith Franklin ${ }^{6}$

$6 \quad{ }^{1}$ World Health Organization Country Office, Ulaanbaatar, Mongolia

$7 \quad{ }^{2}$ Saban Research Institute, Children's Hospital Los Angeles, Los Angeles, California, USA

$8{ }^{3}$ Department of Pediatrics, Keck School of Medicine, University of Southern California, Los

9 Angeles, California, USA

$10{ }^{4}$ Department of Population and Public Health Sciences, Keck School of Medicine, University of

11 Southern California, Los Angeles, California, USA

$12{ }^{5}$ Department of Surveillance and Research, National Center for Maternal and Child Health,

13 Ulaanbaatar, Mongolia

$14{ }^{6}$ Department of Statistical Sciences, University of Toronto, Toronto, Ontario, Canada

\section{Corresponding author:}

19 Name: Temuulen Enebish

20 Email: temuulen@gmail.com

21 Postal address: PO Box 219, PO Office 49, Ulaanbaatar, Mongolia 13381 


\section{Abstract}

23 Ulaanbaatar city (UB), the capital and the home to half of Mongolia's total population, has

24 experienced extreme seasonal air pollution in the past two decades with levels of fine particulate

25 matter with an aerodynamic diameter less than 2.5 micrometers $\left(\mathrm{PM}_{2.5}\right)$ exceeding $500 \mu \mathrm{g} / \mathrm{m}^{3}$ during

26 winter. Based on monitoring data, $\left(\mathrm{PM}_{2.5}\right)$, sulfur dioxide $\left(\mathrm{SO}_{2}\right)$, nitrogen dioxide $\left(\mathrm{NO}_{2}\right)$, and carbon

27 monoxide (CO) exposures were estimated for residential areas across UB using Random Forest

28 models. We collected individual-level data on 1093 stillbirths from UB hospital records (2010-2013)

29 and a surveillance database (2014-2018). Using a time-stratified case-crossover design, we

30 investigated whether short-term increases in daily ambient air pollutants with different exposure lags

31 (2 to 6 days) before delivery were associated with stillbirth. We estimated associations using

32 conditional logistic regression and examined individual-level characteristics for effect modification.

33 During the cold season (Oct-Mar) we observed significantly elevated relative odds of stillbirth per

34 interquartile range increase in mean concentrations of $\mathrm{PM}_{2.5}$ (odds ratio $[\mathrm{OR}]=1.35,95 \%$ confidence

35 interval $[\mathrm{CI}]=1.07-1.71), \mathrm{SO}_{2}(\mathrm{OR}=1.71,95 \% \mathrm{CI}=1.06-2.77), \mathrm{NO}_{2}(\mathrm{OR}=1.30,95 \% \mathrm{CI}=0.99-1.72)$,

36 and $\mathrm{CO}(\mathrm{OR}=1.44,95 \% \mathrm{CI}=1.17-1.77) 6$ days before delivery after adjusting for apparent

37 temperature with a natural cubic spline. The associations of pollutant concentrations with stillbirth

38 were significantly stronger among those younger than 25, nulliparous, and without comorbidities or

39 pregnancy complications during stratified analyses. There was a clear pattern of increased risk for

40 women living in areas of lower socioeconomic status. We conclude that acute exposure to ambient

41 air pollution before delivery may trigger stillbirth, and this risk is higher for certain subsets of

42 women. 


\section{Background}

44 Despite remarkable achievements in women's and children's health in the last 15 years, 2.6

45 million stillbirths in the third trimester occurred worldwide in 2015 (Lawn et al., 2016). Stillbirth was

46 not included in the Millennium Development Goals (United Nations, 2015a) and is still missing

47 from the Sustainable Development goals (United Nations, 2015b). Policies and programs of

48 international and national organizations hardly mention the issue of stillbirth, and it remains an

49 under-financed public health concern. The burden of stillbirth affects women and families by

50 causing psychological and emotional distress and negatively influences communities and society in

51 terms of reduced earnings and increased healthcare expenses. An estimated 4.2 million women live

52 with depression associated with a previous stillbirth (Heazell et al., 2016). Various modifiable risk

53 factors, including maternal age, infectious diseases, lifestyle, and environmental factors, are identified

54 for stillbirth (Lawn et al., 2016). In the past few decades, researchers worldwide have made

55 numerous attempts at ascertaining the effect of environmental exposures such as ambient

56 temperature and air pollution on adverse pregnancy outcomes (Bekkar et al., 2020; Chersich et al.,

57 2020; Klepac et al., 2018). Several reviews summarized the evidence of adverse effects of ambient air

58 pollution on birth outcomes such as preterm birth and low birth weight (Jacobs et al., 2017; Li et al.,

59 2017; Sapkota et al., 2012; Stieb et al., 2012). In contrast, relatively few studies have investigated the

60 association between ambient air pollution and stillbirth. Two recent reviews found suggestive

61 evidence of increased risk of acute and chronic exposure to both gaseous and particulate pollutants

62 on stillbirth occurrence (Siddika et al., 2016; Zhang et al., 2021).

64 matter with an aerodynamic diameter less than 2.5 micrometers $\left(\mathrm{PM}_{2.5}\right)$, may influence fetal survival

65 is not yet well understood, the literature suggests several processes to describe associations between

66 PM and adverse pregnancy outcomes. One possible pathway indicates that free iron ions on particle 
67 surfaces can react with superoxide or hydrogen peroxide to generate highly reactive hydroxyl

68 radicals, which causes excessive oxidative stress that may lead to the degradation of lipids, proteins,

69 and DNA of the placenta (Fortoul et al., 2015). In addition, activation of the inflammatory system

70 may cause PM-mediated oxidative stress. Compounds that adversely affect the immune system

71 promote the release of pro-inflammatory cytokines. In turn, they give a positive feedback loop to

72 form more reactive oxygen species (ROS) and oxidative stress (Al-Gubory et al., 2010). Another

73 potential explanation is that DNA damage induced by pollution may have devastating impacts on a

74 developing fetus whose cells are dividing at a high rate. Studies connecting air pollution to

75 congenital malformations may support this pathway (Padula et al., 2013; Vrijheid et al., 2011). Other

76 studies indicate that air pollution disturbs placental health through injury or inflammation, initiating

77 a severe lack of nutrient transfer between mother and fetus (van den Hooven et al., 2012). To

78 accurately examine the potential mechanistic explanations, additional analyses are required to verify

79 these findings and explore more thoroughly the times during pregnancy when pollutants may impact

80 the fetus resulting in stillbirth.

82 mountains and resultingly prone to atmospheric inversions in the winter, whereby air pollutants are

83 trapped close to the ground unable to become diluted in the mixing layer of the troposphere.

84 Almost $60 \%$ of the city residents used raw coal to heat their home (usually Ger, which is a

85 Mongolian traditional portable dwelling) and cook their meals in cookstoves at the time of this

86 study. This makes UB one of the most polluted cities in the world during winter when there is

87 almost constant atmospheric inversion over the city. Our study area has four major public maternity

88 hospitals that deliver more than $98 \%$ of all babies in the city. This situation makes UB a unique

89 location where we can study the acute association between stillbirth and air pollution in a relatively 
90 cost-effective and timely manner despite the average stillbirth rate in UB being 7.7 per 1000 total

91 births in 2015 (Lawn et al., 2016).

This paper examined the short-term effect of particulate matter on the risk of stillbirth

93 across lags of 2-6 days. We also investigated the effect modification of these associations by

94 socioeconomic risk factors of stillbirth.

\section{Methods}

Ulaanbaatar city registered about 36000 deliveries and 250 stillbirths on average per year

97 between 2010 and 2018 across nine districts, which consist of a varying number of Khoroos (minor

98 administrative units of the city). The current study includes stillbirths occurring between January 1,

99 2010, and December 31, 2018, in 6 contiguous districts (138 Khoroos) of UB. The Institutional

100 Review Boards at the Health Sciences Campus of USC, the Children's Hospital Los Angeles, and the

101 Medical Ethics Committee of the Ministry of Health of Mongolia approved the study design and

102 methods.

\section{Study population}

104 We used two different data sources to collect individual-level stillbirth data. Between 2010

105 and 2013, records were only available at maternity hospital archives in the form of a birth record as

106 there was no official surveillance of stillbirth during this period. In order to collect these data, we

107 hired and trained eight research assistants to help with data abstraction from the paper-based birth

108 records into a computer database. In August 2017, we abstracted the stillbirth data using four two-

109 person teams where one person read paper records, and the other person entered them into the

110 database. Each team member double-checked every record entry. The National Center for Maternal

111 and Child Health (NCMCH) of Mongolia established a Department of Surveillance that conducts

112 nationwide surveillance on maternal and child health indicators in 2014. They use specific forms for 
113 each maternal and child health endpoint to collect data. We obtained individual-level stillbirth data

114 between 2014 and 2018 using the department's electronic database of stillbirth forms. See

115 Supplemental Materials for the translated version of the form.

116 We abstracted the following information from the birth records and the stillbirth form:

117 maternal age, residential address, occupation, gravidity, parity, prenatal care status, delivery hospital,

118 date of stillbirth, fetal gender, weight, length, and gestational age. We used the best obstetric estimate

119 variable on the birth record to determine gestational age, which combines the last menstrual period

120 and ultrasound parameters, as is commonly accepted in clinical practice for gestational age

121 estimation. The Ministry of Health of Mongolia uses the following definition for stillbirth: the birth

122 of a fetus with $\geq 500$ grams weight at or beyond the 22 nd week of gestation and who had no signs of

123 life such as heartbeat, umbilical cord pulse, or muscle movement at birth (Ministry of Health,

124 Guideline for the Calculation and Definition of Main Health Indicators, 2004, page 19). We included

125 stillbirths based on the following criteria: singleton status, maternal residence in one of the six

126 central districts, and delivery at four major public maternity hospitals (Figure 1). We excluded

127 intrapartum stillbirths based on biological plausibility: the definition being a fetal death occurring

128 after the onset of labor and prior to delivery (Tavares Da Silva et al., 2016). Based on the residential

129 Khoroo of each subject, we also obtained Khoroo-level variables such as percentage of households

130 with internet connectivity (a proxy for socioeconomic status) and percentage of Ger households

131 from the UB Office of Statistics, and the number of stoves per square kilometer from the UB Office

132 of Air Pollution Reduction (Narmandakh et al., 2018). 


\section{Geographical distribution of stillbirth cases in Ulaanbaatar, 2010-2018}

Number of stillbirth cases per 100,000 , by khoroo

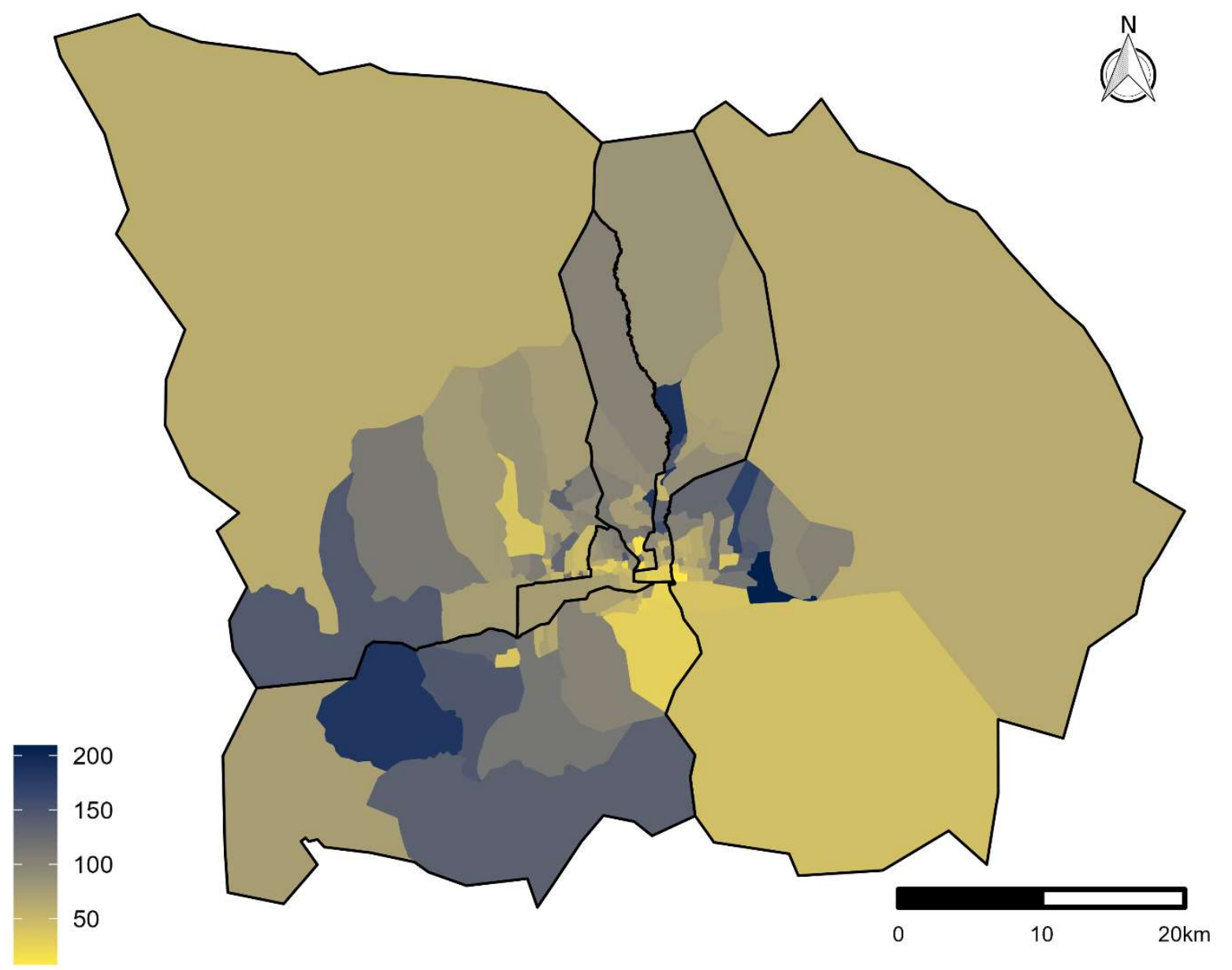

Solid black lines represent 6 contiguous district borders

134 Figure 1. Ulaanbaatar city map of 6 main contiguous districts, the colors represent the rate of stillbirth cases

\section{Exposure data}

We linked daily air pollution concentrations that were estimated using a previously

137 developed and validated spatiotemporal model (Enebish et al., 2020) to the residential Khoroos and

138 for the relevant dates of each stillbirth case. Briefly, our model used ground-level measurements

139 from stationary stations supplemented with multiple spatiotemporal covariates including

140 meteorological (atmospheric temperature, relative humidity, wind speed, wind direction), land use 
141 (length of roads) as well as population (Ger households, stove density), and indicators for time (day

142 of year, season, month). We evaluated six different machine learning algorithms and found that

143 decision trees, particularly Random Forest models, performed the best with leave-one-location-out

144 cross-validation $\mathrm{R}^{2}$ of 0.82 and hold-out test $\mathrm{R}^{2}$ of 0.96 for $\mathrm{PM}_{2.5}$. These Random Forest models

145 were used to predict daily $\mathrm{PM}_{2.5}, \mathrm{SO}_{2}, \mathrm{NO}_{2}$, and $\mathrm{CO}$ concentrations at the centroid of each Khoroo

146 of UB city between 2010 and 2018. In addition, we retrieved meteorological variables from two

147 stations (Chinggis Khaan Intl, Songiin) in UB that send their data to the Global Hourly Integrated

148 Surface Dataset of the National Oceanic and Atmospheric Administration (NOAA National Centers

149 for Environmental Information, n.d.). Using these data, we calculated Apparent Temperature (AT)

150 as either a wind chill index or a heat index depending on the temperature. Wind chill combines

151 temperature and wind velocity to capture how cold the weather feels to the average person when the

152 temperate falls below $0^{\circ} \mathrm{C}$. We used equations used by Environment and Climate Change Canada

153 (Nelson et al., 2002) since Mongolian National Agency for Meteorology and Environmental

154 Monitoring (NAMEM) currently does not have a formula adopted. Depending on air temperature

155 and wind speed, we applied Equation 1 when the temperature of the air was $\leq 0^{\circ} \mathrm{C}$ and the reported

156 wind speed was $\geq 5 \mathrm{~km} / \mathrm{h}$, and Equation 2 when the temperature of the air was $\leq 0^{\circ} \mathrm{C}$ and the

157 reported wind speed was $>0 \mathrm{~km} / \mathrm{h}$ but $<5 \mathrm{~km} / \mathrm{h}$.

$$
W=13.12+0.6215 \times T_{\text {air }}-11.37 \times V_{10 m}^{0.16}+0.3965 \times T_{\text {air }} \times V_{10 m}^{0.16}
$$

$$
W=T_{\text {air }}+\left[\left(-1.59+0.1345 \times T_{\text {air }}\right) / 5\right] \times V_{10 m}
$$


163 Celsius $\left({ }^{\circ} \mathrm{C}\right)$, and $V_{10 m}$ is the wind speed at 10 meters (standard anemometer height), in kilometers 164 per hour $(\mathrm{km} / \mathrm{h})$.

166 obtain perceived temperature when the weather is hot. We used the US National Weather Service

167 algorithm implemented by the R package "weathermetrics" (Anderson et al., 2013) to calculate AT

168 when the atmospheric temperature was more than $5^{\circ} \mathrm{C}$.

\section{Study design}

170 Using a time-stratified case-crossover design, we estimated the relative odds of stillbirth

171 associated with each interquartile range (IQR) increase in mean pollutant concentrations. Maclure

172 first proposed the case-crossover design to study the transient effect of exposure on rare-acute onset

173 disease (Maclure, 1991). Conceptually, the design resembles a combination of retrospective,

174 nonrandomized crossover design and matched case-control design. The main difference is that the

175 case-crossover design only uses a sample of the base population-time by including only cases to

176 allow control of time-independent confounders within subjects. The design derives the effect

177 estimates by comparing exposure before the event with exposure at other control (referent) times.

178 Choosing referent times in case-crossover studies of air pollution is particularly important due to

179 time-dependent confounders, time trends, and autocorrelation in the air pollution exposure. The

180 time-stratified referent scheme is the only referent selection that can avoid overlap bias due to

181 conditional logistic regression estimating equations and time-trend bias by selecting random index

182 dates based on stratification (Janes et al., 2005). We stratified on year, month, and day of the week to

183 control long-term, seasonal, and daily trends using time-stratified referent selection. We selected

184 referent (control) periods as every seventh day during the same month as the stillbirth (case period). 
185 For instance, if the case period was on Wednesday, every other Wednesday in the same month was

186 considered a control period. We looked at lag days between 2 and 6 as possible case periods because

187 it may take an average of 48-70 hours for the deceased fetus to be expelled from the womb (Gardosi

188 et al., 1998; Genest et al., 1992).

\section{Statistical analysis}

190 We utilized conditional logistic regression to estimate the odds ratios (OR) of delivering

191 stillbirth for every IQR increase in $\mathrm{PM}_{2.5}$ on lag days 2 to 6. Models were estimated using a stratified

192 Cox model, with each subject assigned to its stratum (Gail et al., 1981). We adjusted each model

193 with a natural cubic spline (4 degrees of freedom) of the mean apparent temperature on

194 corresponding lag days to control for time-variant meteorological factors and their non-linear

195 relationship with stillbirth as in previous studies (Faiz et al., 2013). We also conducted a seasonally

196 stratified analysis, restricting the models to cases that occurred only in the cold season (October-

197 March), considering the disproportional seasonal variation caused by air pollution emission sources

198 in UB during cold weather (Figure 2). The same models were fit to $\mathrm{SO}_{2}, \mathrm{NO}_{2}$, and $\mathrm{CO}$ with their

199 ORs and 95\% confidence intervals (CIs) scaled to the IQR of each pollutant. We ran stratified

200 analyses based on the following variables to evaluate differential risks of stillbirth by individual case

201 characteristics: maternal age, employment, number of previous pregnancies and deliveries,

202 comorbidity, pregnancy complication as well as residential level covariates such as percentage of Ger

203 households and households with internet connectivity in each subject's living Khoroo. All statistical

204 modeling and geospatial computing were performed in R version 3.6.2 (R Core Team, 2019) using

205 packages "tidyverse" (Wickham et al., 2019), "sf" (Pebesma, 2018), and "survival" (Therneau \&

206 Grambsch, 2000). 
City-wide daily average concentration by season

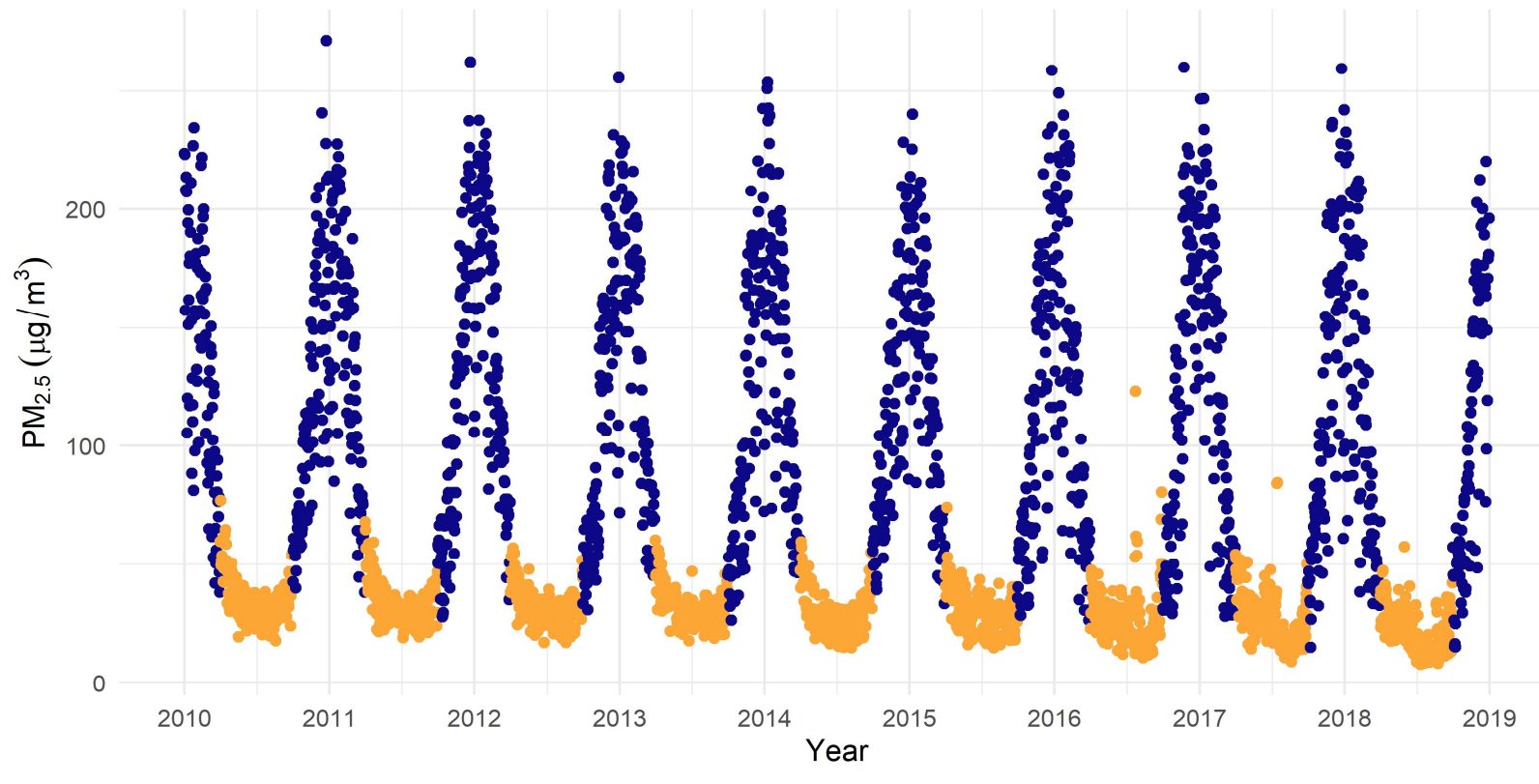

- Cold season (Oct-Mar) - Warm season (Apr-Sep)

208 Figure 2. Seasonal variation of modeled $\mathrm{PM}_{2.5}$ concentration in UB

209 Results

After applying inclusion and exclusion criteria, our study population consisted of 1093

211 stillbirth cases between 2010 and 2018 (Figure 3). 


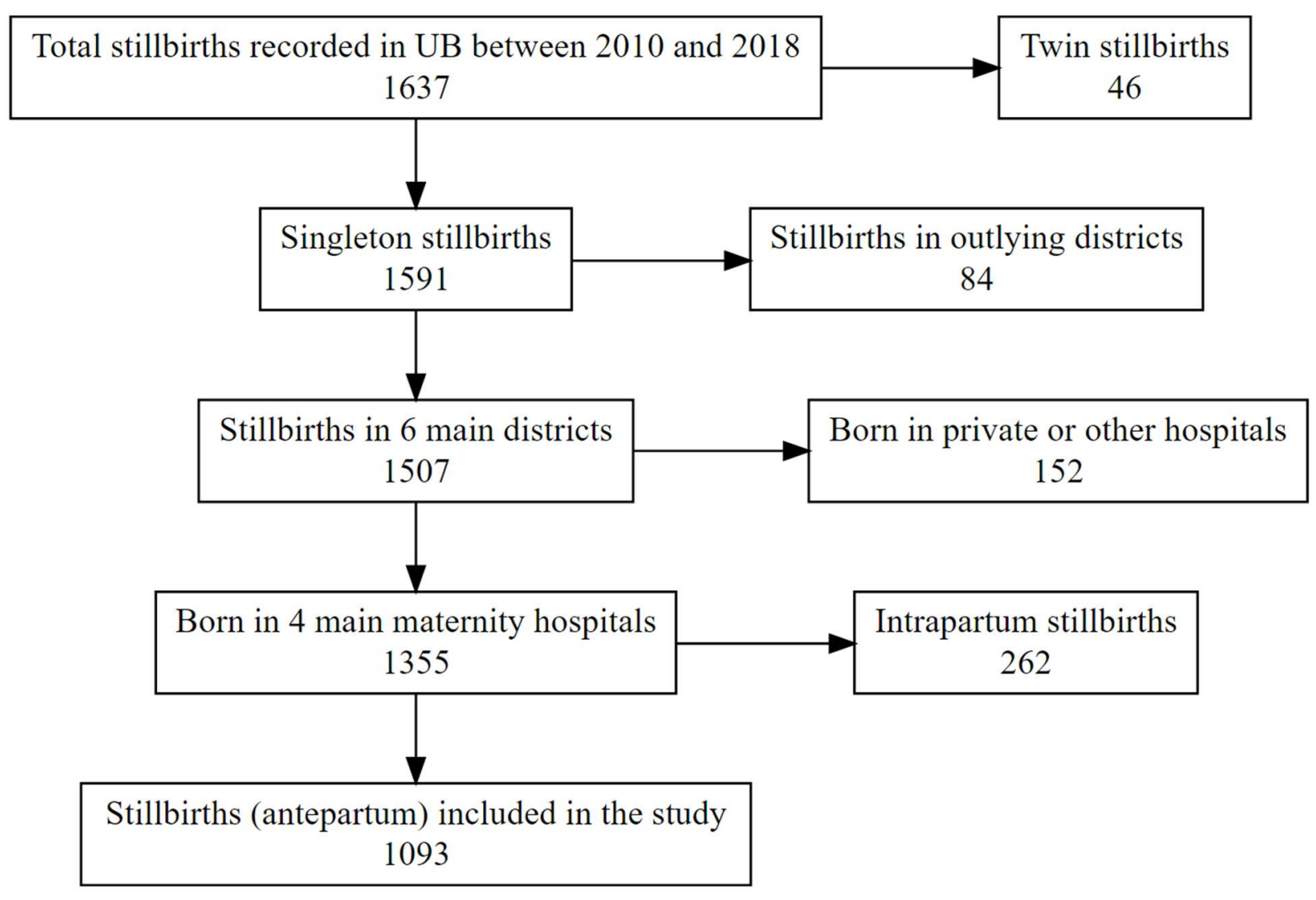

213 Figure 3. Flow chart of the study population

214 Almost a quarter of stillbirths occurred among women aged 35 years or older, and the

215 subjects were divided equally among employed and unemployed status. More than half (54\%) of the

216 women had been pregnant more than two times; however, a third (35\%) of the women had never

217 given birth before. About 65\% of the subjects had one or more pregnancy complications, and

218 approximately half of them had various comorbidities. In terms of fetal variables, there was no

219 dominant fetal gender. The majority weighed less than 2500 grams and had gestational weeks less

220 than 36 weeks (Table 1). Table 1 shows that majority of the cases came from Khoroos with lower

221 internet connectivity, more Ger households, and higher stove density. 
medRxiv preprint doi: https://doi.org/10.1101/2022.02.17.22271117; this version posted February 17, 2022. The copyright holder for this preprint (which was not certified by peer review) is the author/funder, who has granted medRxiv a license to display the preprint in perpetuity.

It is made available under a CC-BY-NC-ND 4.0 International license .

224 Table 1. Characteristics of Mothers and Stillbirths, Ulaanbaatar 2010-2018

\begin{tabular}{|c|c|c|}
\hline & $\begin{array}{c}\text { [ALL] } \\
N=1093\end{array}$ & $\mathbf{N}$ \\
\hline \multicolumn{3}{|l|}{ Maternal covariates } \\
\hline Age (years), N (\%): & & 1093 \\
\hline$<25$ & $286(26.2 \%)$ & \\
\hline $25-34$ & $539(49.3 \%)$ & \\
\hline$>=35$ & $268(24.5 \%)$ & \\
\hline Employment, N (\%): & & 1088 \\
\hline Employed or Student & $574(52.8 \%)$ & \\
\hline Unemployed & $514(47.2 \%)$ & \\
\hline Pregnancies, N (\%): & & 1093 \\
\hline 2 or less & $500(45.7 \%)$ & \\
\hline More than 2 & $593(54.3 \%)$ & \\
\hline Deliveries, N (\%): & & 1092 \\
\hline One or more & $712(65.2 \%)$ & \\
\hline None & $380(34.8 \%)$ & \\
\hline Comorbidities, N (\%) & $504(48.8 \%)$ & 1033 \\
\hline Pregnancy complications, N (\%) & $649(65.2 \%)$ & 995 \\
\hline \multicolumn{3}{|l|}{ Fetal covariates } \\
\hline Gender, N (\%): & & 1092 \\
\hline Female & $528(48.4 \%)$ & \\
\hline Male & $564(51.6 \%)$ & \\
\hline Weight (grams), N (\%): & & 1092 \\
\hline$>=4000$ & $50(4.58 \%)$ & \\
\hline 2500-3999 & $435(39.8 \%)$ & \\
\hline $500-2499$ & $607(55.6 \%)$ & \\
\hline Gestational week, N (\%): & & 1078 \\
\hline 22-26 weeks & $60(5.57 \%)$ & \\
\hline 27-36 weeks & $566(52.5 \%)$ & \\
\hline$>=37$ weeks & $452(41.9 \%)$ & \\
\hline \multicolumn{3}{|l|}{ Residential covariates } \\
\hline Percentage of households with internet connectivity, $\mathrm{N}(\%)$ : & & 1088 \\
\hline $45 \%$ or less & $823(75.6 \%)$ & \\
\hline more than $45 \%$ & $265(24.4 \%)$ & \\
\hline Percentage of Ger households, N (\%): & & 1088 \\
\hline $20 \%$ or less & $266(24.4 \%)$ & \\
\hline more than $20 \%$ & $822(75.6 \%)$ & \\
\hline Stoves (per sq.km.), N (\%): & & 1088 \\
\hline 15 stoves or less & $271(24.9 \%)$ & \\
\hline more than 15 stoves & $817(75.1 \%)$ & \\
\hline
\end{tabular}


medRxiv preprint doi: https://doi.org/10.1101/2022.02.17.22271117; this version posted February 17, 2022. The copyright holder for this preprint (which was not certified by peer review) is the author/funder, who has granted medRxiv a license to display the preprint in perpetuity.

It is made available under a CC-BY-NC-ND 4.0 International license .

2263 and 6 days before delivery for all pollutants examined (Table 2 and Figure 4). Odds ratios on lag

227 day 6 were generally higher than the estimates on lag day 3. Only carbon monoxide had a statistically

228 significant elevated risk on lag day six at $\alpha=0.05$ significance level. In models restricted to the cold

229 season, most effect estimates except $\mathrm{NO}_{2}$ increased considerably. Previously non-significant odds

230 ratios on lag day 6 in overall models reached statistical significance for $\mathrm{PM}_{2.5}$ (OR:1.35, 95\% CI:1.07-

231 1.71) and $\mathrm{SO}_{2}$ (OR:1.71, 95\% CI:1.06-2.77). We also found a statistically significant increased risk of

232 stillbirth per IQR increase in mean $\mathrm{PM}_{2.5} 3$ days before delivery (Figure 4).

233 Table 2. Relative Odds of Stillbirth Associated with IQR Increases in Mean $\mathrm{PM}_{2.5}, \mathrm{NO}_{2}$, $\mathrm{SO}_{2}$, and $\mathrm{CO}$

234 Concentration by Lag day(s)

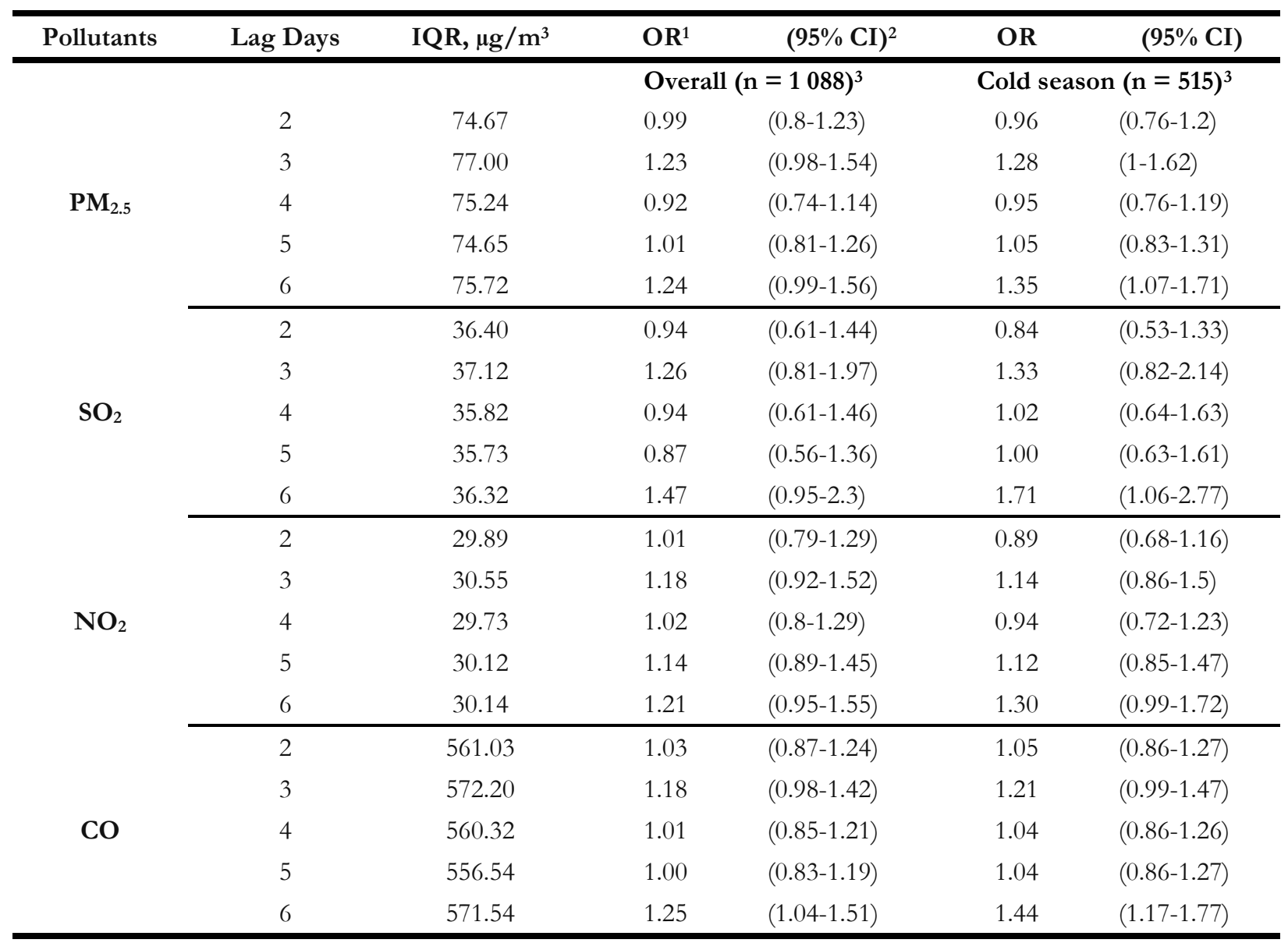

${ }^{1}$ Odds Ratio

$295 \%$ Confidence Interval

${ }^{3}$ Models are adjusted for the apparent temperature of the corresponding lag day 
$\mathrm{PM}_{2.5}$

Overall

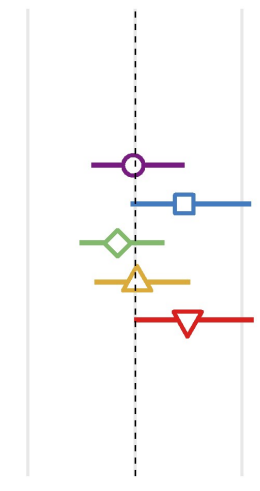

0.5

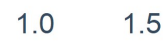

2.0

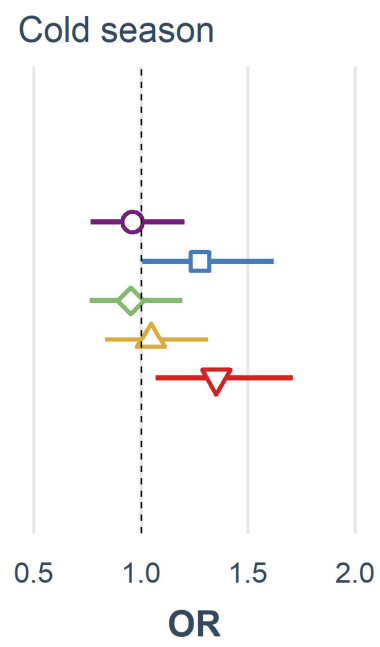

$\mathrm{SO}_{2}$

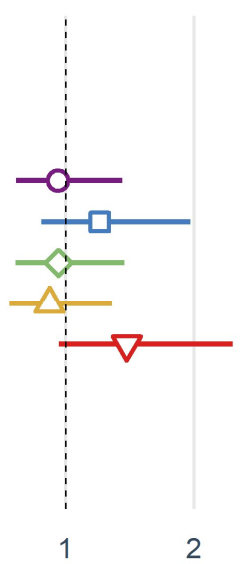

$\mathrm{NO}_{2}$
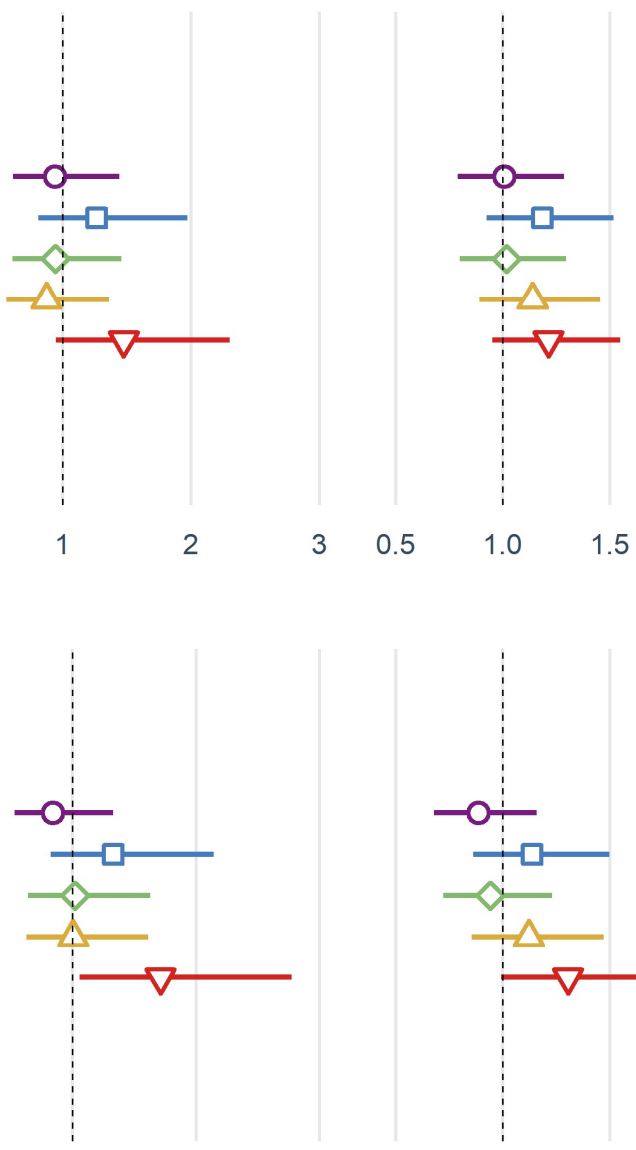

1

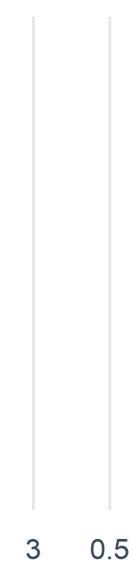

1.0
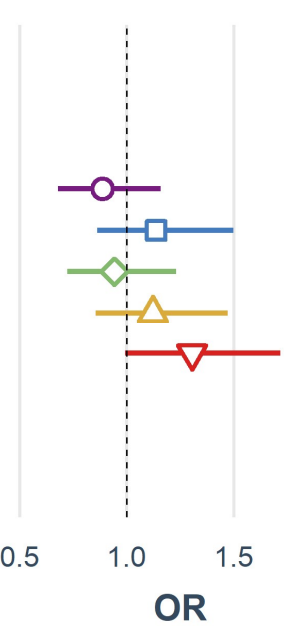

$\mathrm{CO}$
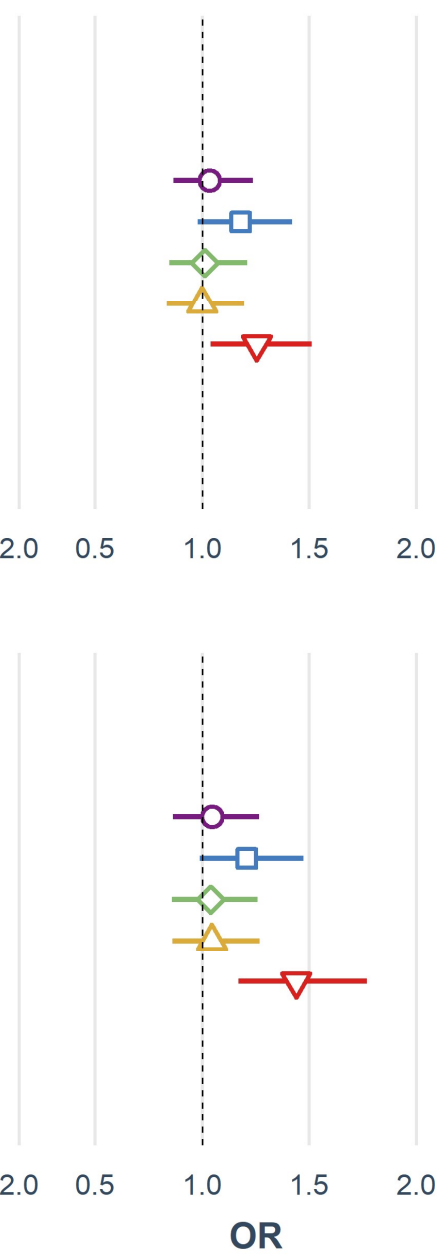

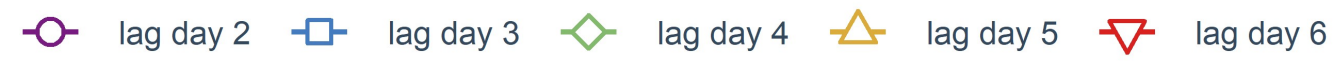

236

237

238 stratified models (Table 3) show significant differences in odds ratios between various maternal and

239 residential characteristics. They reveal stronger associations for younger, unemployed women with

240 fewer pregnancies and women who had never given birth before. Interestingly, we also found higher

Figure 4. Effect estimates of air pollution on stillbirth risk

Possible modifiers of the effect associated with stillbirth and pollutants examined in

241 odds ratios for women without comorbidities and pregnancy complications. On the other hand, 
medRxiv preprint doi: https://doi.org/10.1101/2022.02.17.22271117; this version posted February 17, 2022. The copyright holder for this preprint (which was not certified by peer review) is the author/funder, who has granted medRxiv a license to display the preprint in perpetuity.

It is made available under a CC-BY-NC-ND 4.0 International license .

242 living in a Khoroo with a larger proportion of Ger households and households without internet

243 connectivity and higher stove density was associated with higher relative odds of stillbirth.

244 Table 3. Relative Odds of Stillbirth Associated with IQR Increase in $\mathrm{PM}_{2.5}, \mathrm{NO}_{2}, \mathrm{SO}_{2}$, and CO Concentration

245 on Lag Day 6 by Level of Maternal Characteristics

\begin{tabular}{|c|c|c|c|c|c|c|c|c|}
\hline & \multicolumn{2}{|c|}{$\mathbf{P M}_{2.5}$} & \multicolumn{2}{|r|}{$\mathrm{SO}_{2}$} & \multicolumn{2}{|c|}{$\mathrm{NO}_{2}$} & \multicolumn{2}{|r|}{$\mathrm{CO}$} \\
\hline Characteristic & OR & $(95 \% \mathrm{CI})$ & OR & $(95 \% \mathrm{CI})$ & OR & $(95 \% \mathrm{CI})$ & OR & $(95 \% \mathrm{CI})$ \\
\hline \multicolumn{9}{|l|}{ Maternal age (years) } \\
\hline$<25$ & 1.45 & $(0.94-2.25)$ & 2.38 & $(1.02-5.57)$ & 1.22 & $(0.8-1.88)$ & 1.52 & $(1.04-2.21)$ \\
\hline $25-34$ & 1.19 & $(0.86-1.66)$ & 1.25 & $(0.65-2.4)$ & 1.20 & $(0.83-1.73)$ & 1.21 & $(0.91-1.6)$ \\
\hline$>=35$ & 1.17 & $(0.77-1.78)$ & 1.20 & $(0.51-2.83)$ & 1.21 & $(0.73-2.02)$ & 1.15 & $(0.81-1.62)$ \\
\hline \multicolumn{9}{|c|}{ Maternal employment } \\
\hline Unemployed & 1.43 & $(1.01-2.03)$ & 1.89 & $(0.98-3.62)$ & 1.53 & $(1.06-2.2)$ & 1.49 & $(1.11-1.98)$ \\
\hline Employed or Student & 1.12 & $(0.83-1.51)$ & 1.19 & $(0.64-2.2)$ & 0.98 & $(0.7-1.37)$ & 1.12 & $(0.87-1.43)$ \\
\hline \multicolumn{9}{|c|}{ Number of pregnancies } \\
\hline 2 or less & 1.67 & $(1.19-2.34)$ & 2.59 & $(1.33-5.03)$ & 1.40 & $(1-1.96)$ & 1.54 & $(1.15-2.04)$ \\
\hline More than 2 & 0.98 & $(0.73-1.33)$ & 0.92 & $(0.51-1.68)$ & 1.04 & $(0.73-1.48)$ & 1.07 & $(0.84-1.38)$ \\
\hline \multicolumn{9}{|l|}{ Number of deliveries } \\
\hline None & 1.74 & $(1.2-2.52)$ & 2.76 & $(1.32-5.77)$ & 1.39 & $(0.96-2.01)$ & 1.64 & $(1.2-2.23)$ \\
\hline 1 or more & 1.02 & $(0.77-1.36)$ & 1.00 & $(0.57-1.76)$ & 1.08 & $(0.78-1.49)$ & 1.07 & $(0.84-1.35)$ \\
\hline \multicolumn{9}{|l|}{ Maternal comorbidity } \\
\hline Yes & 1.13 & $(0.83-1.55)$ & 1.07 & $(0.56-2.05)$ & 1.13 & $(0.81-1.6)$ & 1.25 & $(0.96-1.62)$ \\
\hline No & 1.39 & $(1-1.93)$ & 1.97 & $(1.05-3.7)$ & 1.23 & $(0.86-1.77)$ & 1.25 & $(0.95-1.64)$ \\
\hline \multicolumn{9}{|c|}{ Pregnancy complication } \\
\hline Yes & 1.12 & $(0.84-1.5)$ & 1.17 & $(0.67-2.03)$ & 1.07 & $(0.79-1.46)$ & 1.05 & $(0.82-1.34)$ \\
\hline No & 1.46 & $(0.98-2.19)$ & 2.44 & $(1.07-5.58)$ & 1.56 & $(1-2.44)$ & 1.57 & $(1.11-2.23)$ \\
\hline \multicolumn{9}{|c|}{ Percentage of households with internet connection } \\
\hline $45 \%$ or less & 1.37 & $(1.05-1.78)$ & 1.81 & $(1.1-2.97)$ & 1.29 & $(0.98-1.69)$ & 1.41 & $(1.13-1.77)$ \\
\hline more than $45 \%$ & 0.99 & $(0.65-1.51)$ & 0.53 & $(0.19-1.5)$ & 0.86 & $(0.49-1.53)$ & 0.94 & $(0.65-1.35)$ \\
\hline \multicolumn{9}{|c|}{ Percentage of Ger households } \\
\hline $20 \%$ or less & 1.10 & $(0.72-1.68)$ & 0.80 & $(0.28-2.28)$ & 1.04 & $(0.62-1.74)$ & 0.89 & $(0.61-1.3)$ \\
\hline more than $20 \%$ & 1.32 & $(1.01-1.72)$ & 1.63 & $(1-2.68)$ & 1.25 & $(0.94-1.65)$ & 1.42 & $(1.14-1.77)$ \\
\hline \multicolumn{9}{|l|}{ Stoves (per sq.km.) } \\
\hline 15 stoves or less & 0.93 & $(0.61-1.44)$ & 0.58 & $(0.2-1.66)$ & 0.81 & $(0.49-1.35)$ & 0.83 & $(0.56-1.23)$ \\
\hline more than 15 stoves & 1.39 & $(1.07-1.81)$ & 1.77 & $(1.08-2.9)$ & 1.37 & $(1.03-1.82)$ & 1.42 & $(1.14-1.77)$ \\
\hline
\end{tabular}

Estimates significant at the 0.05 significance level are bolded

\section{Discussion}

247 We found a substantially increased risk of stillbirth associated with IQR increases in the

248 mean concentrations of all examined pollutants 3 and 6 days before delivery. These associations 
249 were controlled for time-varying confounders such as atmospheric temperature, relative humidity,

250 and wind velocity in the form of apparent temperature. Under a time-stratified case-crossover

251 design, time-invariant confounders such as individual-level maternal, fetal, and residential attributes

252 and seasonal, monthly, and day-of-the-week time trends could not have influenced our results. Our

253 stratified analyses showed a disproportionately higher risk for women living in low-income Ger

254 districts than in apartments. They also indicate that younger women who have not given birth before

255 and have no comorbidities and pregnancy complications are at increased risk of stillbirth associated

256 with ambient air pollution.

The biological mechanisms underlying the effect of air pollutants on stillbirth risk have

258 varying levels of evidence depending on the pollutant. On the one hand, there is well-established

259 toxicity of carbon monoxide on the fetus (Penney, 1996). Two main pathways are reduction of

260 oxygen-carrying capacity of maternal hemoglobin by CO, which leads to oxygen shortage in fetal

261 blood (Salam et al., 2005), and higher affinity of fetal hemoglobin for binding CO than adult

262 hemoglobin that further compromises the oxygen delivery (Sangalli et al., 2003). On the other, we

263 have scarce evidence of how exactly $\mathrm{NO}_{2}$ and $\mathrm{SO}_{2}$ might affect fetal death. There is evidence for

264 crossing the placental barrier, affecting cell division, and activating hypoxic injury or immune-

265 mediated damage (Al-Gubory et al., 2010; Proietti et al., 2013). There have been several hypotheses

266 regarding their effect on a fetus for particulate matter. Major ones are a compromise of maternal

267 blood and nutrients delivery, DNA damage and inflammation via contribution to oxidative stress,

268 and lowering the transplacental function by increasing the concentration of DNA adducts (Perera et

269 al., 1992). Timing of exposure to particulate matter along fetal developmental periods may also lead

270 to varying effects due to differences in physiologic maturity of the fetus (Perera et al., 1999). 
272 pregnancy outcomes, relatively few investigated the effect on stillbirth. Even fewer studies focused

273 on the acute effects of air pollution on stillbirth risk. A time-series study in Sao Paulo, Brazil,

274 examined the association between daily counts of intrauterine mortality (gestational duration of $>28$

275 weeks) and ecological measures of daily ambient air pollutants. They found increased short-term

276 (less than five days) risk of intrauterine mortality for $\mathrm{NO}_{2}\left(\beta=0.0013 / \mu \mathrm{g} / \mathrm{m}^{3} ; p<0.01\right), \mathrm{SO}_{2}$

$277\left(\beta=0.0005 / \mu \mathrm{g} / \mathrm{m}^{3} ; p<0.10\right)$ and $\mathrm{CO}(\beta=0.0223 / \mathrm{ppm} ; p<0.10)$ using Poisson regression adjusted for

278 season and weather (Pereira et al., 1998). This study, to our knowledge, is the first to look at the

279 short-term effect of air pollutants on stillbirth risk and remains an essential part of the evidence base

280 despite its limitations due to ecological design and imperfect case definition.

A study by Faiz et al. utilized time-stratified referent selection in a case-crossover design to

282 look at the triggering effect of ambient air pollution on stillbirth in New Jersey, US (Faiz et al.,

283 2013). They found significantly increased relative odds of stillbirth on lag day 2 per IQR increase in

284 mean concentrations of $\mathrm{CO}(\mathrm{OR}=1.20,95 \% \mathrm{CI}=1.05-1.37)$ and $\mathrm{SO}_{2}(\mathrm{OR}=1.11,95 \% \mathrm{CI}=1.02-$

285 1.22) and increased odds ratios for IQR increases in $\mathrm{NO}_{2}(\mathrm{OR}=1.11,95 \% \mathrm{CI}=0.97-1.26)$ and

$286 \mathrm{PM}_{2.5}(\mathrm{OR}=1.07,95 \% \mathrm{CI}=0.93-1.22)$ levels. Similar increases in stillbirth risk were also observed

287 for cumulative averages on days 2 to 6 , and they did not observe effect modifications by maternal

288 characteristics. The current study tries to emulate the above study conceptually to investigate the

289 acute effect of ambient air pollutants on the risk of stillbirth. Our findings agree on increased short-

290 term risk of stillbirth associated with IQR increase in the pollutants. They, however, differ in terms

291 of which lag day has the highest risk and the magnitude of the risk. We found increased relative odds

292 of stillbirth on lag days 3 and 6 for all pollutants, and the ORs were amplified when restricted to the

293 cold season only. Unfortunately, there was almost no overlap between individual maternal risk

294 factors between the studies to compare stratified analyses. 
296 have been published. Mendola et al. used retrospective cohort data across 12 clinical centers in the

297 US. They investigated the acute and chronic effects of air pollutants on the risk of stillbirth at the

298 community level using Poisson regression with generalized estimating equations. They observed that

299 acute exposure to ozone was associated with a 13-22\% increased risk of stillbirth on lag days 2, 3,

300 and 5-7 (Mendola et al., 2017). A time-series study in Ahvaz, Iran, by Dastoorpoor et al. used a

301 distributed lag non-linear model estimated by quasi-Poisson regression to investigate the acute

302 effects of air pollution (per 10-unit increase) on stillbirth and other adverse pregnancy outcomes.

303 They looked at single-day lags of 1 and 2 and cumulative lag days 0 through 14 and did not find an

304 increased effect estimate, but rather an inverse association with ozone on lag day 1 and 2 and with

$305 \mathrm{SO}_{2}$ on lag day 2 (Dastoorpoor et al., 2018). A recent addition to the evidence base on the short-

306 term effects of ambient air pollution on stillbirth risk came from California. They used population-

307 weighted centroids to link ground monitoring station data to the maternal residential zip code to

308 assign air pollution exposure. Similar to New Jersey and our study, the authors utilized a time-

309 stratified case-crossover design to estimate the short-term effects and found an increased risk of

310 stillbirth per IQR increase in $\mathrm{SO}_{2}, \mathrm{O}_{3}$, and $\mathrm{PM}_{10-2.5}$ concentrations (Sarovar et al., 2020).

312 acknowledge several differences. The magnitude of the effect that we observed is substantially larger

313 than the studies mentioned above. We believe this is primarily because of the large IQR stemming

314 from high air pollution levels during cold months in UB. Unfortunately, this change in daily air

315 quality over days and weeks during winter in UB is in line with the significant health and mortality

316 burden of air pollution found in previous studies. Allen et al. estimated conservatively that 1 in 10

317 deaths in UB are due to air pollution using land-use regression models and mobile monitoring to

318 assess exposure (Allen et al., 2013). At the same time, researchers from the National Center for 
319 Maternal and Child Health $(\mathrm{NCMCH})$ found a strikingly high seasonal correlation between

320 miscarriage and air pollution levels in the city (Enkhmaa et al., 2014).

The main improvement of our study over previous literature comes from our individual-

322 level exposure assessment with fine spatial and temporal resolution. The main challenge in

323 conducting air pollution epidemiology studies in low to middle income countries is the difficulty of

324 accurately assessing exposure due to inadequate and unreliable measurements provided by scarce

325 pollutant monitoring stations. Our previous work demonstrated the feasibility and advantages of

326 utilizing machine learning algorithms to capture complex relationships between air pollution and

327 other meteorological, land use, and population-level variables in a low-resource setting with sparse

328 monitoring capacity (Enebish et al., 2020). This work allowed us to assign air pollution exposure to

329 every subject in our study based on their residential area and relevant days. Although exposure

330 measurement errors are unavoidable when we try to estimate personal exposure using modeling

331 based on ambient air pollution levels, we believe this approach has significantly improved over

332 previous methods of assigning exposures. But the error will result in non-differential

333 misclassification, likely leading to a bias towards the null. We should also mention that we evaluated

334 various modifiable maternal risk factors that previous studies have not been able to investigate. This

335 opportunity is mainly thanks to the manual data collection process from birth records and stillbirth

336 form information provided by the Surveillance Department of NCMCH. The limitations of our

337 current study include exposure assessment at the residential area (Khoroo) level, the uncertain

338 estimate for the date of fetal death based on the delivery date, and possible residual confounding due

339 to imperfect measurement of apparent temperature.

341 delivery for every IQR increase in mean concentrations of $\mathrm{PM}_{2.5}, \mathrm{SO}_{2}, \mathrm{NO}_{2}$, and $\mathrm{CO}$. This 
medRxiv preprint doi: https://doi.org/10.1101/2022.02.17.22271117; this version posted February 17, 2022. The copyright holder for this preprint (which was not certified by peer review) is the author/funder, who has granted medRxiv a license to display the preprint in perpetuity. It is made available under a CC-BY-NC-ND 4.0 International license .

342 association was strengthened when we restricted the analysis to only the cold season. Future studies

343 with finer spatial and temporal exposure, time-varying confounder assessment, and better case

344 identification are necessary to elucidate further the underlying mechanism of the markedly adverse

345 effects of air pollution on stillbirth. 


\section{References}

347 Al-Gubory, K. H., Fowler, P. A., \& Garrel, C. (2010). The roles of cellular reactive oxygen species, oxidative stress and antioxidants in pregnancy outcomes. International Journal of Biochemistry and Cell Biology, 42(10), 1634-1650. https://doi.org/10.1016/j.biocel.2010.06.001

Allen, R. W., Gombojav, E., Barkhasragchaa, B., Byambaa, T., Lkhasuren, O., Amram, O., Takaro, T. K., \& Janes, C. R. (2013). An assessment of air pollution and its attributable mortality in Ulaanbaatar, Mongolia. Air Quality, Atmosphere and Health, 6(1), 137-150. https://doi.org/10.1007/s11869-011-0154-3

Anderson, G. B., Bell, M. L., \& Peng, R. D. (2013). Methods to calculate the heat index as an exposure metric in environmental health research. Environmental Health Perspectives, 121(10),

Bekkar, B., Pacheco, S., Basu, R., \& DeNicola, N. (2020). Association of Air Pollution and Heat Exposure With Preterm Birth, Low Birth Weight, and Stillbirth in the US: A Systematic Review. JAMA Network Open, 3(6), e208243. temperatures in pregnancy and risk of preterm birth, low birth weight, and stillbirths: Systematic review and meta-analysis. BMJ, 371, m3811. https://doi.org/10.1136/bmj.m3811 spontaneous abortion, premature delivery, and stillbirth in Ahvaz, Iran: A time-series study. Environmental Science and Pollution Research, 25(6), 5447-5458. https://doi.org/10.1007/s11356-017-0692-9 
Enebish, T., Chau, K., Jadamba, B., \& Franklin, M. (2020). Predicting ambient PM2.5

Enkhmaa, D., Warburton, N., Javzandulam, B., Uyanga, J., Khishigsuren, Y., Lodoysamba, S., spontaneous abortion in Mongolia. BMC Pregnancy and Childbirth, 14(1), 146.

Faiz, A. S., Rhoads, G. G., Demissie, K., Lin, Y., Kruse, L., \& Rich, D. Q. (2013). Does Ambient Air Pollution Trigger Stillbirth? Epidemiology, 24(4), 538-544. https://doi.org/10/f42tzs

Fortoul, T. I., Rodriguez-Lara, V., Gonzalez-Villalva, A., Rojas-Lemus, M., Colin-Barenque, L., https://doi.org/10/gb8xz5

Gail, M. H., Lubin, J. H., \& Rubinstein, L. V. (1981). Likelihood calculations for matched casecontrol studies and survival studies with tied death times. Biometrika, 68(3), 703-707. antepartum stillbirths. British Journal of Obstetrics and Gynaecology, 105(5), 524-530. https://doi.org/10.1111/j.1471-0528.1998.tb10153.x and Gynecology, 80(4), 575-584. 
Heazell, A. E. P., Siassakos, D., Blencowe, H., Burden, C., Bhutta, Z. A., Cacciatore, J., Dang, N., Das, J., Flenady, V., Gold, K. J., Mensah, O. K., Millum, J., Nuzum, D., O’Donoghue, K., Redshaw, M., Rizvi, A., Roberts, T., Saraki, H. E. T., Storey, C., ... Downe, S. (2016). Stillbirths: Economic and psychosocial consequences. The Lancet, 387(10018), 604-616. https://doi.org/10/f3tsrv

Jacobs, M., Zhang, G., Chen, S., Mullins, B., Bell, M., Jin, L., Guo, Y., Huxley, R., \& Pereira, G. (2017). The association between ambient air pollution and selected adverse pregnancy

Janes, H., Sheppard, L., \& Lumley, T. (2005). Overlap bias in the case-crossover design, with application to air pollution exposures. Statistics in Medicine, 24(2), 285-300.

Klepac, P., Locatelli, I., Korošec, S., Künzli, N., \& Kukec, A. (2018). Ambient air pollution and outcomes in China: A systematic review. Science of the Total Environment, 579, 1179-1192.

408 Lawn, J. E., Blencowe, H., Waiswa, P., Amouzou, A., Mathers, C., Hogan, D., Flenady, V., Frøen, J. 
review and meta-analysis. Environmental Pollution, 227, 596-605.

418 Maclure, M. (1991). The Case-Crossover Design: A Method for Studying Transient Effects on the Risk of Acute Events. 133(2), 144-153.

420 Mendola, P., Ha, S., Pollack, A. Z., Zhu, Y., Seeni, I., Kim, S. S., Sherman, S., \& Liu, D. (2017).

424 Narmandakh, L., Galymbek, K., \& Tsatsral, B. (2018). Report on 2018 Enumeration of Air Pollution

429 Nelson, C. A., Tew, M., Phetteplace, G., Schwerdt, R., Maarouf, A., Osczevski, R., Bluestein, M.,

433 Padula, A. M., Tager, I. B., Carmichael, S. L., Hammond, S. K., Lurmann, F., \& Shaw, G. M. (2013).

437 Pebesma, E. (2018). Simple Features for R: Standardized Support for Spatial Vector Data. The R Journal, 10(1), 439-446. https://doi.org/10.32614/RJ-2018-009

Penney, D. G. (1996). Carbon Monoxide. CRC-Press. 
444 Perera, F. P., Hemminki, K., Gryzbowska, E., Motykiewicz, G., Michalska, J., Santella, R. M., damage in humans from environmental pollution in Poland. Nature, 360(6401), 256.

Perera, F. P., Jedrychowski, W., Rauh, V., \& Whyatt, R. M. (1999). Molecular epidemiologic research on the effects of environmental pollutants on the fetus. Environmental Health Perspectives, 107

454 R Core Team. (2019). R: A language and environment for statistical computing. https://www.R-project.org/

455 Salam, M. T., Millstein, J., Li, Y.-F., Lurmann, F. W., Margolis, H. G., \& Gilliland, F. D. (2005). 
Sapkota, A., Chelikowsky, A. P., Nachman, K. E., Cohen, A. J., \& Ritz, B. (2012). Exposure to particulate matter and adverse birth outcomes: A comprehensive review and meta-analysis. Air Quality, Atmosphere and Health, 5(4), 369-381. https://doi.org/10/bjdd2c

Sarovar, V., Malig, B. J., \& Basu, R. (2020). A case-crossover study of short-term air pollution exposure and the risk of stillbirth in California, 1999-2009. Environmental Research, 191,

Siddika, N., Balogun, H. A., Amegah, A. K., \& Jaakkola, J. J. K. (2016). Prenatal ambient air pollution exposure and the risk of stillbirth: Systematic review and meta-analysis of the

471 Stieb, D. M., Chen, L., Eshoul, M., \& Judek, S. (2012). Ambient air pollution, birth weight and preterm birth: A systematic review and meta-analysis. Environmental Research, 117, 100-111.

474 Tavares Da Silva, F., Gonik, B., McMillan, M., Keech, C., Dellicour, S., Bhange, S., Tila, M., Harper,

475 D. M., Woods, C., Kawai, A. T., Kochhar, S., \& Munoz, F. M. (2016). Stillbirth: Case definition and guidelines for data collection, analysis, and presentation of maternal

478 Therneau, T. M., \& Grambsch, P. M. (2000). The Cox Model. In T. M. Therneau \& P. M. Grambsch (Eds.), Modeling Survival Data: Extending the Cox Model (pp. 39-77). Springer.

481 United Nations. (2015a). The Millennium Development Goals Report. United Nations, 72. https:/ / doi.org/978-92-1-101320-7 
van den Hooven, E. H., Pierik, F. H., de Kluizenaar, Y., Hofman, A., van Ratingen, S. W., Zandveld, V. (2012). Air pollution exposure and markers of placental growth and function: The Generation R Study. Environmental Health Perspectives, 120(12), 1753-1759. Nieuwenhuijsen, M. (2011). Ambient air pollution and risk of congenital anomalies: A systematic review and meta-analysis. Environmental Health Perspectives, 119(5), 598-606. https://doi.org/10/fb2ved

495 Wickham, H., Averick, M., Bryan, J., Chang, W., McGowan, L. D., Fran ois, R., Grolemund, G., Hayes, A., Henry, L., Hester, J., Kuhn, M., Pedersen, T. L., Miller, E., Bache, S. M., M९ller, K., Ooms, J., Robinson, D., Seidel, D. P., Spinu, V., ... Yutani, H. (2019). Welcome to the tidyverse. Journal of Open Source Software, 4(43), 1686. https://doi.org/10/ggddkj

499 Zhang, H., Zhang, X., Wang, Q., Xu, Y., Feng, Y., Yu, Z., \& Huang, C. (2021). Ambient air pollution and stillbirth: An updated systematic review and meta-analysis of epidemiological studies. Environmental Pollution, 278, 116752. https://doi.org/10.1016/j.envpol.2021.116752 